ORIGINAL ARTICLE

\title{
Effects on respiratory health of a reduction in air pollution from vehicle exhaust emissions
}

\author{
M L Burr, G Karani, B Davies, B A Holmes, K L Williams
}

Occup Environ Med 2004;61:212-218. doi: 10.1136/oem.2002.003244

See end of article for authors' affiliations

.....................

Correspondence to:

$\operatorname{Dr} M$ L Burr, Department of Epidemiology, Statistics \& Public Health, University of Wales College of

Medicine, Heath Park,

Cardiff CF14 4XN, UK.

burrml@cf.ac.uk

Accepted 17 April 2003

\begin{abstract}
Aims: To determine whether residents of congested streets have a higher prevalence of respiratory symptoms than residents of nearby uncongested streets, and whether their respiratory health improves following a reduction in exposure to traffic related air pollutants.

Methods: An area was identified where certain streets were subject to air pollution from heavy road traffic, which was likely to improve following the construction of a by-pass. A respiratory survey was conducted among the residents, together with the residents of nearby uncongested streets, at baseline and again a year after the by-pass opened. Measurements were made of air pollutant concentrations in both areas on both occasions.

Results: Initial concentrations of $\mathrm{PM}_{10}$ and $\mathrm{PM}_{2.5}$ were substantially higher in the congested than in the uncongested streets. When the by-pass opened, the volume of heavy goods traffic fell by nearly $50 \%$. $\mathrm{PM}_{10}$ decreased by $23 \%\left(8.0 \mu \mathrm{g} / \mathrm{m}^{3}\right)$ in the congested streets and by $29 \%\left(3.4 \mu \mathrm{g} / \mathrm{m}^{3}\right)$ in the uncongested streets, with similar proportionate falls in $\mathrm{PM}_{2.5}$. There were no clear or consistent differences between the residents of the two areas initially in terms of symptoms or peak flow variability. Repeat questionnaires were obtained from 165 and 283 subjects in the congested and uncongested areas respectively, and showed a tendency for most symptoms to improve in both areas. For chest symptoms, the improvement tended to be greater in the uncongested area, although the difference between the areas was not statistically significant. Rhinitis and rhinoconjunctivitis tended to improve to a greater extent in the congested streets; the difference between the areas was significant for the degree to which rhinitis interfered with daily activities. Peak flow variability tended to improve in the uncongested area.

Conclusions: The by-pass reduced pollutant levels to a degree that probably alleviates rhinitis and rhinoconjunctivitis but has little effect on lower respiratory symptoms.
\end{abstract}

po recent decades there has been increasing concern about possible adverse effects of pollution by motor vehicle emissions. Among these concerns has been a belief that this type of air pollution may cause or aggravate asthma and other respiratory disorders. ${ }^{1}$ This belief has gained wide acceptance among the general public, who attribute the rise in asthma prevalence to the increasing volume of road traffic.

There is a large body of epidemiological evidence on the relation between atmospheric pollution and respiratory illness. It is not in doubt that exposure to severe air pollution causes respiratory symptoms, or that long term exposure can lead to chronic disease. Day-to-day fluctuations in pollutant concentrations are associated with variations in hospital admissions and death rates for respiratory and cardiac conditions, probably because of acute effects in susceptible persons. ${ }^{2}$ What is less clear is the health effect of continued exposure to pollutants from motor vehicles in concentrations that occur in association with heavy traffic in ordinary weather conditions, as distinct from episodes of severe pollution. Here the epidemiological findings are less consistent.

On the one hand, several studies have suggested that respiratory illness (particularly asthma) or reduced lung function is associated with proximity to main roads, road traffic density, or exposure to pollutants derived from motor vehicles. $^{3-11}$ Police officers ${ }^{12}$ and street cleaners ${ }^{13}$ who are occupationally exposed to traffic fumes tend to have more respiratory symptoms than comparable persons not so exposed.

On the other hand, several studies have failed to show any association between the prevalence of asthma and exposure to traffic derived air pollution. Among British children aged 12-14 years, the prevalence of wheeze is slightly lower in metropolitan than in non-metropolitan areas; ${ }^{14}$ it is as high in the Highlands of Scotland as elsewhere, and particularly high in Skye, where air pollution (apart from ozone) is very low. ${ }^{15}$ Surveys of adults within England ${ }^{16}$ and France $^{17}$ suggest that the prevalence of asthma is similar in urban and rural areas. International comparisons show certain paradoxes: asthma is very common in New Zealand, where the air is unpolluted, and uncommon in Athens, where the air is heavily polluted by car exhaust fumes. ${ }^{18} 19$ Several studies showed no association between asthma and traffic volume. ${ }^{20-22}$ A review did not find consistent associations for all symptom outcomes across studies, and recommended further work before definite conclusions can be drawn about adverse effects of living along major roads. ${ }^{23}$

Epidemiological evidence is susceptible to confounding bias, in that people who live in polluted areas may well differ from other people in ways that influence their liability to disease. Experimental investigations are necessarily restricted to short term studies and cannot elucidate the effects of continued exposure. The only possibility of investigating such effects, avoiding confounding bias, is to make use of a "natural experiment", when a change in pollutant exposure can be predicted and its effects monitored prospectively. The

Abbreviations: $\mathrm{Cl}$, confidence interval; $\mathrm{CV}$, coefficient of variation HGV, heavy goods vehicle; PEFR, peak expiratory flow rate; $\mathrm{PM}_{2.5}$, particulate matter of $<2.5 \mu \mathrm{m}$ aerodynamic diameter; $\mathrm{PM}_{10}$, particulate matter of $<10 \mu \mathrm{m}$ aerodynamic diameter; SD, standard deviation 


\section{Main messages}

- The opening of the by-pass led to a substantial reduction in the volume of heavy goods vehicles using streets that had been subject to traffic congestion.

- Atmospheric concentrations of particles decreased in the congested streets; proportionate reductions occurred in nearby uncongested streets, where the concentrations were substantially lower.

- Lower respiratory symptoms tended to improve in both areas; it is doubtful whether the improvements can be attributed to the by-pass, since they were usually greater in the uncongested streets.

- Symptoms of rhinitis and rhinoconjunctivitis also tended to improve in both areas, the effect usually being greater in the congested streets.

- Relieving traffic congestion to this extent reduces air pollution to a degree that may alleviate nasal and ocular symptoms but probably has little effect on lower respiratory health.

present study was set up to examine the changes in pollutant exposure and respiratory health that were expected to occur consequent upon the opening of a by-pass around an area subject to heavy traffic congestion.

The study was designed to address two questions:

- Are people who are frequently exposed to vehicle exhaust fumes more liable than other people to have respiratory symptoms?

- Does respiratory health improve following a reduction in exposure to air pollutants from vehicle exhaust fumes?

\section{METHODS}

An area in North Wales was identified where it was anticipated that severe traffic congestion would be relieved by the opening of a by-pass. For much of its length, the main road through this area is flanked by houses that open directly on to the street, so that the inhabitants are likely to be exposed to traffic derived pollution whenever they go out. There are also a number of shops and small business premises where the workers are likely to have a similar degree of exposure. For comparison, uncongested streets within the same general area were selected, containing houses of a similar age and type, in order to control for factors such as weather and influenza epidemics. The area lies within a small town (population just under 23 000) that is characterised by general (including some heavy) industry.

Traffic was counted in the congested area, in twelve 15minute periods between 8 am and $10 \mathrm{pm}$, on 5-10 days in each season before and after the by-pass opened. The average counts were calculated separately for cars, vans, and heavy goods vehicles (HGVs). All counts were made by the same observer (GK).

Measurements of fine and coarse particles $\left(\mathrm{PM}_{2.5}\right.$ and $\mathrm{PM}_{10}$ ) were made at fixed sites in the congested and uncongested streets. In each area the air was sampled from a point within a metre of the kerbside, at the level of a first floor window. In the uncongested area, this was in a side street about 20 metres away from the congested street. Measurements were made continuously for three weeks in July 1996 and January 1997, and for two weeks in November 1996 and April 1997. The aerosols were collected on preweighed polypropylene backed $37 \mathrm{~mm}$ Teflon filters using a

\section{Policy implications}

- Among the potential benefits of schemes to reduce traffic congestion to this degree, the effects on health are likely to be fairly modest.

- Plans for future by-passes and other schemes to reduce traffic congestion should include arrangements to monitor the health effects.

Graseby-Anderson dichotomous sampler, and $47 \mathrm{~mm}$ membrane filters using a Grimm real time analyser.

Residents in the congested and uncongested streets were asked to take part in a survey of chest disease. Workers in shops and offices were also invited to participate. The explanatory letter did not mention the issue of traffic congestion, so as not to introduce unnecessary bias. A nurse (BD) visited the houses and asked each resident to complete a questionnaire enquiring about respiratory symptoms during the past year, medical consultations, smoking habits, and other details. Parents were asked to complete similar questionnaires on behalf of their children. At the same time, adult subjects were issued with peak flow meters for 2 3 weeks, and asked to record their peak expiratory flow rate (PEFR) on getting up each morning and on coming in (or during the evening) later in the day. The local research ethics committee approved the study, and signed consent forms were obtained for all participating subjects.

After the by-pass opened, the traffic counts and fixed site pollutant measurements were repeated for the same periods of time at the same seasons as before, using the same methodology. Subjects who had recorded PEFR were issued with peak flow meters at the same times of year as before, and recordings made in the same way. When at least a year had elapsed since the by-pass opened, the questionnaire was readministered to the subjects who participated in the first phase of the study.

The answers from the two questionnaires were then compared. For each symptom, the subjects who improved or deteriorated were defined as those whose reporting of that symptom had changed, either by occurring on one occasion but not on the other, or in respect of the severity of the symptom. The net percentage of subjects who improved was calculated for the congested and uncongested streets; the difference between the two areas was expressed as improvement in the congested streets minus improvement in the uncongested streets, with 95\% confidence intervals (CIs) calculated by the method of squaring and adding. ${ }^{24} 25$

\section{RESULTS}

Four hundred premises were identified in the congested streets, of which 45 were empty or for sale and so ineligible for the study. Among those premises that were presumed to be eligible, no contact was made with the occupants of 90 (mostly because they were seldom at home during the daytime); in 76 the occupants declined to participate, and in 14 no useful information was obtained about the occupants' health. In the uncongested streets 505 premises were identified, of which 67 were empty or for sale; in 143 the occupants were not contacted, in 76 they declined to participate, and in 35 no useful information was obtained about their health. Thus in 1996-97 health information was obtained from 175 premises in the congested streets $(49.3 \%$ of those presumed to be eligible) and 184 in the uncongested streets $(42.0 \%)$. These percentages underestimate the response rates, owing to the substantial numbers where no contact was made with the occupants; some of these 
premises may in fact have been ineligible. Seventy five of the participating premises in the congested streets, and 11 in the uncongested streets, were businesses (offices or shops) where the occupants did not live on site.

There was a delay in the opening of the by-pass, owing to engineering difficulties with a bridge. Whereas it had been expected that the by-pass would open in the spring or early summer of 1997, it opened on 6 March 1998. In consequence, the repeat questionnaires were administered from April 1999 until February 2000, since they enquired about symptoms during the past 12 months. Many of the subjects who participated in the first phase had moved away by this time, so the numbers available for comparison were less than expected. This was particularly true of the streets that had been congested; residents who intended to move had delayed doing so until the by-pass opened, in order to obtain a better price for their houses.

Table 1 shows that the average hourly HGV count in the congested streets fell by nearly 50\% after the opening of the by-pass. Counts of cars and vans (not shown) also tended to decline, although to a lesser extent. The table also shows mean $\mathrm{PM}_{10}$ levels, as measured at the fixed monitoring sites by the Graseby-Anderson device. At baseline, the concentration in the congested streets was about three times higher than that in the uncongested streets. After the by-pass opened, the mean concentration decreased during all seasons in the congested area, by about $23 \%$ overall; the proportionate fall was slightly greater in the uncongested streets, but their pollution levels were still only a third of those in the congested streets, which showed much greater falls in absolute terms $\left(8.0 \mu \mathrm{g} / \mathrm{m}^{3}\right.$ compared with $\left.3.4 \mu \mathrm{g} / \mathrm{m}^{3}\right)$. A similar pattern was shown by the $\mathrm{PM}_{2.5}$ concentrations.

Baseline information was obtained from 386 subjects in the congested streets and 425 in the uncongested streets. Table 2 shows the prevalence of various symptoms. Subjects with "speech limiting wheeze" are those who reported that in the past 12 months wheeze had ever been severe enough to limit speech to only one or two words at a time between breaths. "Winter cough" denotes a cough in the winter that occurs on most days for as much as three months each year; a similar definition applies to "winter phlegm". "Rhinitis" was defined as a problem with sneezing or a runny or blocked nose in the past 12 months without a cold; "rhinoconjunctivitis" denotes this problem accompanied by itchy-watery eyes, also in the past 12 months. The prevalence of asthma, hay fever, and rhinitis and most other symptoms was similar in the two groups; the only significant difference related to rhinitis that interfered with daily activities, the prevalence being higher in the congested area $(\mathrm{p}<0.05)$.

Table 3 shows the results of the PEFR data at baseline. It was decided to use the coefficient of variation (CV) of each individual's PEFR readings as an index of airflow variability. Fluctuations in airflow are characteristic of asthma and other wheezy conditions, and can be taken as an objective indication of the degree of variable airway resistance in an individual. Subjects whose records covered less than five days are excluded from this analysis. The CV (shown as a percentage) "on getting up" was lower in subjects living in the congested streets; the difference between the two areas "on coming in" was much less. Thus there is no objective evidence of any greater tendency to asthma in the congested streets-rather the reverse.

There were 165 and 283 subjects in the congested and uncongested streets respectively who provided information before and after the by-pass opened $(42.7 \%$ and $66.6 \%$ respectively of the original respondents). Table 4 shows certain characteristics of the original groups at baseline, and of the subsets who participated on both occasions. There was a greater tendency for younger people to leave the congested than the uncongested streets during the interval, but little or no differential loss with relation to gender, single person dwelling, smoking habit, wheeze, or rhinitis.

Table 5 shows changes in the reporting of various symptoms in those individuals who completed questionnaires in 1996-97 and also in 1999-2000. Subjects who failed to answer a question on either occasion are excluded from that analysis, so the numbers vary slightly from one symptom to another. In each case the "net \% better" is the number of persons who improved minus the number who deteriorated, expressed as a percentage of the total available. Some questions (on number of attacks, sleep disturbance, and effect on activities) allowed graded answers that distinguished degrees of severity; the others enquired simply about presence or absence of the symptom. Figure l shows the percentages of people who improved and deteriorated with respect to wheeze, cough, rhinoconjunctivitis, and rhinitis interfering with daily activities. In general, there was a tendency for the number who improved to exceed the number who deteriorated in both areas. For indices of wheeze, without exception the subjects in the congested streets showed a lower net improvement than those in the uncongested streets, although the differences between the areas were small. Very little net change occurred in the prevalence of chronic cough or phlegm in either area. There was, however, a marked improvement in both areas in the numbers of subjects who consulted a doctor for chest trouble. Rhinitis tended to improve in both areas; the improvement was greater in the congested than in the uncongested streets, significantly so for interference with daily activities $(\mathrm{p}<0.05)$.

Table 6 shows the peak flow data, again expressed as CVs, of those persons who recorded their PEFR on at least five days in both phases of the study. The hypothesis was that CV would decline with a reduction in air pollution. In fact, the $\mathrm{CV}$ tended to increase slightly in the congested streets and to decrease in the uncongested streets, where the change on getting up was statistically significant.

\section{DISCUSSION}

The experimental method is not usually feasible in investigating the effects of air pollution, except for those that are very short term. There is therefore an important place for studies that make use of "natural experiments", when a change in exposure can be predicted and its consequences observed. This situation arose when a by-pass was planned that would relieve traffic congestion in a definable area.

\begin{tabular}{|c|c|c|c|c|c|c|}
\hline & \multicolumn{3}{|c|}{ Congested streets } & \multicolumn{3}{|c|}{ Uncongested streets } \\
\hline & 1996-97 & 1998-99 & Change & 1996-97 & $1998-99$ & Change \\
\hline HGVs per hour & 74 & 39 & $-46.9 \%$ & & & \\
\hline $\mathrm{PM}_{10}\left(\mu \mathrm{g} / \mathrm{m}^{3}\right)$ & 35.2 & 27.2 & $-22.7 \%$ & 11.6 & 8.2 & $-28.9 \%$ \\
\hline $\mathrm{PM}_{2.5}\left(\mu \mathrm{g} / \mathrm{m}^{3}\right)$ & 21.2 & 16.2 & $-23.5 \%$ & 6.7 & 4.9 & $-26.6 \%$ \\
\hline
\end{tabular}


Table 2 Initial prevalence of symptoms in congested and uncongested streets

\begin{tabular}{|c|c|c|c|c|}
\hline \multirow[b]{2}{*}{ Symptom } & \multicolumn{2}{|c|}{ Congested streets $(n=386)$} & \multicolumn{2}{|c|}{ Uncongested streets $(n=425)$} \\
\hline & No. & $\%$ & No. & $\%$ \\
\hline Wheeze & 131 & 33.9 & 138 & 32.5 \\
\hline$>3$ attacks & 56 & 14.5 & 69 & 16.3 \\
\hline Sleep disturbed at least 1 night/week & 35 & 9.1 & 28 & 6.6 \\
\hline Speech limiting wheeze & 22 & 5.7 & 25 & 5.9 \\
\hline $\begin{array}{l}\text { Wheeze interfered with activities } \\
\text { more than a little }\end{array}$ & 29 & 7.5 & 20 & 4.7 \\
\hline Wheeze without a cold & 79 & 20.8 & 76 & 18.1 \\
\hline Asthma ever & 59 & 15.3 & 60 & 14.3 \\
\hline Treatment for wheeze or asthma & 58 & 15.1 & 64 & 15.4 \\
\hline Winter cough & 59 & 15.6 & 83 & 20.1 \\
\hline Winter phlegm & 46 & 12.2 & 63 & 15.5 \\
\hline Saw doctor for chest trouble & 93 & 24.9 & 104 & 25.6 \\
\hline Rhinitis without a cold & 143 & 37.3 & 161 & 38.3 \\
\hline Rhinoconjunctivitis & 81 & 21.1 & 72 & 17.1 \\
\hline $\begin{array}{l}\text { Rhinitis interfered with activities } \\
\text { more than a little }\end{array}$ & 29 & 7.6 & 17 & 4.1 \\
\hline Hay fever ever & 78 & 20.6 & 89 & 21.2 \\
\hline Eczema ever & 67 & 17.7 & 73 & 17.3 \\
\hline
\end{tabular}

As expected, the initial concentrations of atmospheric $\mathrm{PM}_{10}$ and $\mathrm{PM}_{2.5}$ were substantially higher in the congested than in the uncongested streets. Following the opening of the by-pass, there was a clear and sustained change in the pattern of traffic using the streets that had been subject to traffic congestion. The most obvious difference was the reduction in the number of HGVs using these roads; over the year, this fell to just over a half of the previous volume. This decline was presumably the major cause of the fall in the concentration of atmospheric particles. In the congested area both $\mathrm{PM}_{10}$ and $\mathrm{PM}_{2.5}$ levels fell in every season, by about $23 \%$ over the year. It is noteworthy that the uncongested area showed similar (or slightly greater) proportionate declines in particle levels, suggesting that pollutants in both areas had a common source.

The study was designed primarily to examine the changes that occurred over time, rather than as a comparison between two areas. The uncongested area was included so as to detect changes that might arise from factors (such as epidemics or unusual weather) other than the relief of traffic congestion attributable to the by-pass. Nevertheless, the baseline data allow some comparisons to be made between the areas. They may not provide a representative picture of the population, since the response rates were low, though as these were fairly similar in the two areas the data may still be comparable. Since the purpose was to study the effects of exposure to local conditions, little attempt was made to contact people who seemed to be seldom at home. Consequently the study population is likely to have contained a higher proportion of

Table 3 Peak flow variability at baseline

\begin{tabular}{|c|c|c|}
\hline & Congested streets & Uncongested streets \\
\hline \multicolumn{3}{|l|}{ On getting up } \\
\hline No. subjects & 202 & 182 \\
\hline Mean no. days & 13.6 & 12.0 \\
\hline Mean CV of PEFR (SD) & $5.25(3.40)$ & $6.40(4.26)$ \\
\hline $95 \% \mathrm{Cl}$ & 4.78 to 5.72 & 5.78 to 7.02 \\
\hline \multicolumn{3}{|l|}{ On coming in } \\
\hline No. subjects & 189 & 179 \\
\hline Mean no. days & 11.5 & 13.3 \\
\hline Mean CV of PEFR (SD) & $5.37(3.83)$ & $5.85(3.66)$ \\
\hline $95 \% \mathrm{Cl}$ & 4.83 to 5.92 & 5.31 to 6.39 \\
\hline
\end{tabular}

persons at home during the day, and so potentially affected by local conditions to a greater extent, than the occupants of the premises excluded from the study.

It might have been expected that the subjects in the congested streets would have had a higher prevalence of respiratory symptoms and a greater peak flow variability than those in the uncongested streets. Some studies have shown such a relation, but others have not. In the present study there were no consistent associations between symptoms and area; contrary to expectation, peak flow variability on getting up was significantly greater in the uncongested streets. It is conceivable that persons who found they were affected by traffic fumes had moved away from the congested area before the study began, since traffic flow had been heavy there for many years.

There were fewer subjects than expected who were available for the before-and-after comparison. This was because a high proportion of the original residents were no longer resident or willing to participate when contacted again for the second stage of the survey. The loss was greatest among the younger subjects, so that the mean age was higher for the comparative part of the study. The problem was made worse by the delay in the completion of the by-pass. The data therefore do not exclude the possibility that a larger number of subjects would show effects that are not evident here. There was no evidence of selective bias arising from differential losses of persons who lived alone, smoked, or reported symptoms at baseline.

With regard to the chest symptoms (wheeze, cough, and phlegm), the overall tendency was for people in both areas to improve. It seems unlikely that this improvement can be attributed to the fall in atmospheric particulate levels, since it was usually greater in the uncongested streets, where the decline in particulates was less in absolute terms. The reported improvement was more probably due to other factors, such as differences in weather or incidence of respiratory infections between the two years. These findings illustrate the importance of including a control population when attempting to attribute time trends to a change in one specific factor.

A different pattern emerged with relation to nasal and ocular symptoms. Here again the overall tendency was for people in both areas to improve, but the trend was greater in the congested streets. The difference between the areas was statistically significant for interference with daily activities by 
Table 4 Baseline characteristics of the original groups of respondents and of the subsets who provided before-and-after information

\begin{tabular}{|c|c|c|c|c|}
\hline & \multicolumn{2}{|c|}{ Congested streets } & \multicolumn{2}{|c|}{ Uncongested streets } \\
\hline & Original group & Subset & Original group & Subset \\
\hline Number & 386 & 165 & 425 & 283 \\
\hline Mean age (SD), y & $37.9(20.0)$ & $47.9(16.5)$ & $38.4(23.2)$ & $40.2(22.9)$ \\
\hline Aged $>65$ y $(\%)$ & $33(8.5)$ & $22(13.3)$ & $62(14.6)$ & $41(14.5)$ \\
\hline Male (\%) & $156(40.4)$ & $65(39.4)$ & $168(39.5)$ & $114(40.3)$ \\
\hline $\begin{array}{l}\text { In single person dwelling } \\
(\%)\end{array}$ & $20(5.2)$ & $7(4.2)$ & $36(8.5)$ & $20(7.1)$ \\
\hline Smoker (\%) & $96(24.9)$ & $40(24.4)$ & $114(26.8)$ & $72(25.4)$ \\
\hline Wheeze (\%) & 131 (33.9) & $47(28.5)$ & $138(32.5)$ & $84(29.7)$ \\
\hline Rhinitis (\%) & 143 (37.3) & $62(38.5)$ & $161(38.3)$ & $108(38.6)$ \\
\hline
\end{tabular}

rhinitis without a cold $(\mathrm{p}<0.05)$. It is of course possible that this was a chance finding, in view of the number of associations being examined. However, the similar trends for reported rhinitis and rhinoconjunctivitis together with the difference at baseline suggest that there may be an effect attributable to the reduction in particulate exposure consequent on the opening of the by-pass.

The PEFR variability tended to increase slightly in the congested streets, though not to a degree that was statistically significant. Thus it provides no evidence for any improvement attributable to the by-pass, although not excluding that possibility. In the uncongested streets the variability decreased, significantly so "on getting up". This accords with the tendency for chest symptoms to improve particularly in these streets. It is possible that these improvements were attributable to the by-pass, since a reduction in pollutants occurred in the uncongested streets. But such an effect would be more likely to appear "on coming in" and in the congested streets, where the decline in pollutant concentrations was greater. It therefore seems more probable that these improvements were due to other factors.

Published studies show a remarkable lack of consistency regarding the relation between air pollution from road traffic and asthma, wheeze, or atopy. Even a severe episode of air pollution does not necessarily provoke an epidemic of asthma: an exceptional rise in the concentrations of $\mathrm{NO}_{2}$ and particles in London had no discernible effect on hospital admissions for asthma. ${ }^{26}$ Given the likely operation of publication bias in favour of studies that show a relation, the true effect of traffic related pollutants on asthma is probably small. It is therefore not surprising that in the present study there was no obvious reduction in wheeze or asthma attributable to the relief of traffic congestion with the opening of the by-pass.

There is some evidence that lower respiratory symptoms, including cough and phlegm, are associated with atmospheric particulates, especially those with a diameter of less than $2.5 \mu \mathrm{m}\left(\mathrm{PM}_{2.5}\right)$. In the Harvard Six City Diary Study (USA), the reporting of cough, phlegm, chest pain, or wheeze by schoolchildren was significantly related to an interquartile increment of $\mathrm{PM}_{2.5}$ over the course of five months. ${ }^{27}$ However, this increment amounted to $15 \mu \mathrm{g} / \mathrm{m}^{3}$, substantially more than the change in the congested streets $(5.0 \mu \mathrm{g} /$ $\mathrm{m}^{3}$ overall) in the present study. It seems unlikely that a change of this size will have an important effect on lower respiratory symptoms.

It is in relation to nasal and ocular symptoms that vehicle exhaust fumes probably have their greatest effects. Surveys in Germany $^{28}$ and Japan ${ }^{29}$ have shown a higher prevalence of allergic rhinitis in areas with heavy pollution from automobile exhausts. In Helsinki, nasal congestion occurred on more days among children living in central than in suburban areas, and was related to their personal exposure to $\mathrm{NO}_{2}$, attributed to proximity of automobile traffic. ${ }^{30}$ A study of volunteers found that the most prominent symptoms during exposure to diesel exhaust were irritation of the eyes and nose and an unpleasant smell. ${ }^{31}$ These reports accord with the findings of the present study, where the greatest net improvement in the health of residents of the congested streets was in terms of rhinitis and rhinoconjunctivitis.

In attempting to draw conclusions from this study, it is important to acknowledge the following limitations:

Table 5 Net improvement in symptom prevalence in congested and uncongested streets

\begin{tabular}{|c|c|c|c|c|c|c|c|c|c|}
\hline \multirow[b]{2}{*}{ Symptom in past year } & \multicolumn{4}{|c|}{ Congested streets } & \multicolumn{4}{|c|}{ Uncongested streets } & \multirow{2}{*}{$\begin{array}{l}\text { Difference* in net \% } \\
\text { better }(95 \% \mathrm{Cl})\end{array}$} \\
\hline & Total no. & Better & Worse & Net $\%$ better & Total no. & Better & Worse & Net $\%$ better & \\
\hline \multicolumn{10}{|l|}{ Wheeze } \\
\hline Any & 165 & 17 & 16 & 0.6 & 283 & 35 & 15 & 7.1 & $-6.5(-14.9$ to 2.0$)$ \\
\hline No. attacks & 163 & 21 & 21 & 0 & 282 & 45 & 21 & 8.5 & $-8.5(-18.2$ to 1.2$)$ \\
\hline Disturbs sleep & 164 & 12 & 11 & 0.6 & 283 & 26 & 18 & 2.8 & $-2.2(-9.9$ to 5.5$)$ \\
\hline Limits speech & 164 & 4 & 2 & 1.2 & 282 & 12 & 7 & 1.8 & $-0.6(-5.2$ to 4.5$)$ \\
\hline Affects activities & 165 & 13 & 12 & 0.6 & 281 & 26 & 14 & 4.3 & $-3.7(-11.3$ to 4.0$)$ \\
\hline Without a cold & 162 & 12 & 15 & -1.9 & 281 & 17 & 18 & -0.4 & $1.5(-6.2$ to 9.3$)$ \\
\hline Treated & 163 & 8 & 5 & 1.8 & 264 & 18 & 11 & 2.7 & $-0.8(-7.1$ to 5.6$)$ \\
\hline Winter cough & 156 & 14 & 11 & 1.9 & 261 & 15 & 14 & 0.4 & $1.5(-6.2$ to 9.3$)$ \\
\hline Winter phlegm & 144 & 10 & 10 & 0 & 253 & 12 & 12 & 0 & $0(-7.6$ to 7.6$)$ \\
\hline Consulted doctor & 140 & 18 & 10 & 5.7 & 247 & 29 & 18 & 4.5 & $1.3(-8.1$ to 10.7$)$ \\
\hline \multicolumn{10}{|l|}{ Rhinitis } \\
\hline Any & 161 & 27 & 9 & 11.2 & 280 & 40 & 22 & 6.4 & $5.4(-3.1$ to 15.0$)$ \\
\hline Involves eyes & 163 & 17 & 6 & 6.7 & 279 & 19 & 18 & 0.4 & $6.4(-0.9$ to 13.8$)$ \\
\hline Affects activities & 161 & 27 & 4 & 14.3 & 276 & 33 & 22 & 4.0 & $10.3(3.1$ to 17.3$)$ \\
\hline Treated & 161 & 12 & 10 & 1.2 & 278 & 26 & 22 & 1.4 & $-0.2(-5.2$ to 7.5$)$ \\
\hline
\end{tabular}



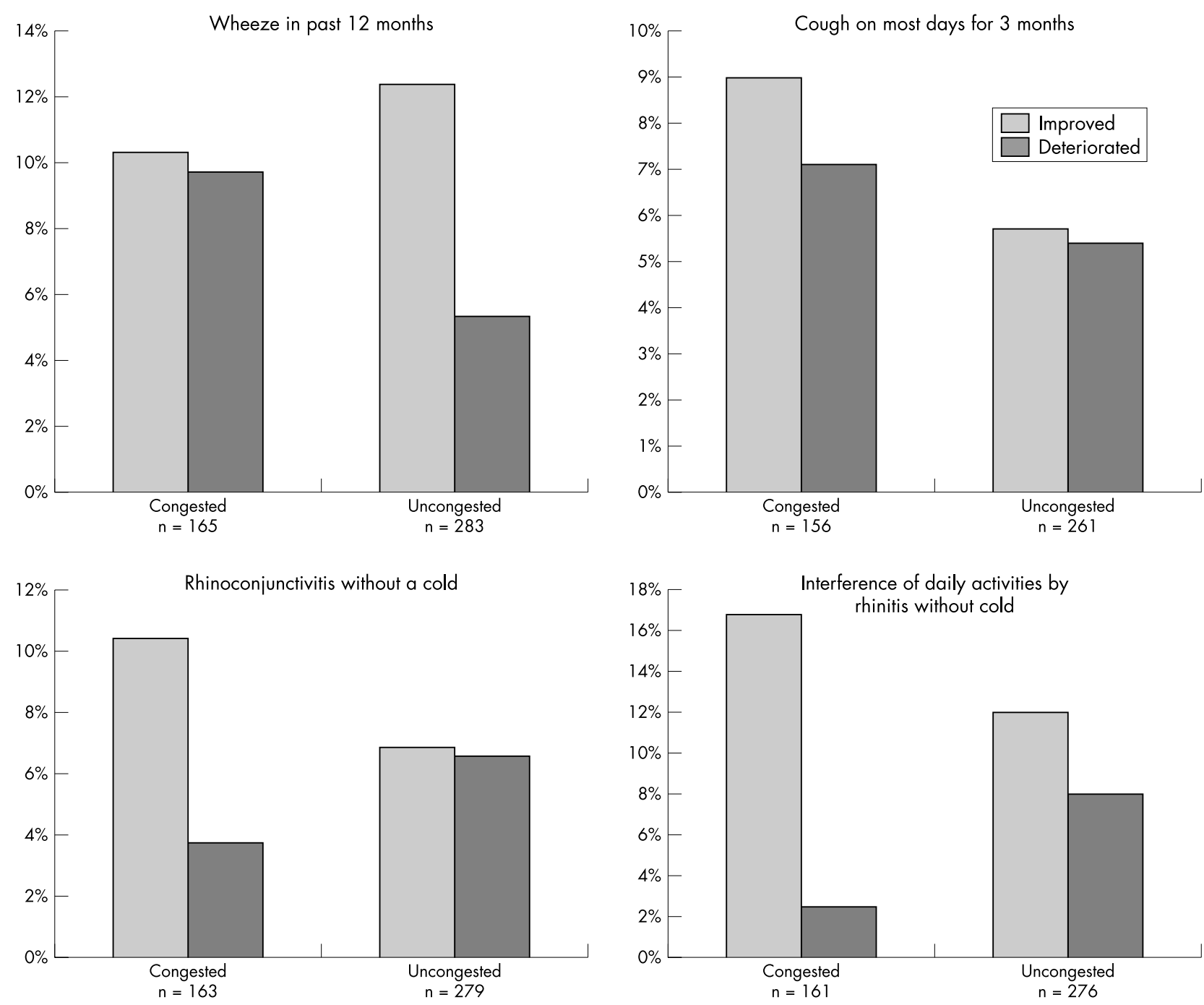

Figure 1 Percentages of subjects whose symptoms improved or deteriorated.

- The effect may have been larger if the difference in atmospheric pollution between the congested and uncongested streets had initially been greater. Most of the latter

\begin{tabular}{|c|c|c|}
\hline & Congested streets & Uncongested streets \\
\hline \multicolumn{3}{|l|}{ On getting up } \\
\hline No. subjects & 81 & 99 \\
\hline $\begin{array}{l}\text { Mean CV in } \\
1996-97 \text { (SD) }\end{array}$ & $5.09(3.31)$ & $6.17(3.88)$ \\
\hline $\begin{array}{l}\text { Mean CV in } \\
1998-99 \text { (SD) }\end{array}$ & $5.32(4.35)$ & $4.99(3.54)$ \\
\hline $\begin{array}{l}\text { Mean change in } \\
\mathrm{CV} \text { (SD) }\end{array}$ & $+0.23(4.52)$ & $-1.18(3.83)$ \\
\hline $95 \% \mathrm{Cl}$ & $-0.75,+1.21$ & $-1.93,-0.43$ \\
\hline \multicolumn{3}{|l|}{ On coming in } \\
\hline No. subjects & 79 & 95 \\
\hline $\begin{array}{l}\text { Mean CV in } \\
1996-97 \text { (SD) }\end{array}$ & $5.09(3.47)$ & $5.77(3.60)$ \\
\hline $\begin{array}{l}\text { Mean CV in } \\
1998-99 \text { (SD) }\end{array}$ & $5.25(4.07)$ & $5.22(3.67)$ \\
\hline $\begin{array}{l}\text { Mean change } \\
\text { in } C V(S D)\end{array}$ & $+0.16(3.60)$ & $-0.55(3.36)$ \\
\hline $95 \% \mathrm{Cl}$ & $-0.63,+0.95$ & $-1.23,+0.13$ \\
\hline
\end{tabular}

streets were rather close to the former, in an attempt to compare households of similar type.

- The difference in pollutant exposure between subjects in the two areas was probably reduced by the tendency for subjects in the uncongested streets to visit the congested area for shopping and other services, even though few of them actually worked there.

- The reduction in traffic, and hence in pollutant concentrations, was only modest. If there had been a greater decline in pollutants, an effect on lower respiratory symptoms might have occurred.

- The concurrent decline in pollutant levels in the uncongested streets was larger than expected, and may have masked an effect in the congested streets attributable to the by-pass. The tendency for symptoms to improve in the uncongested area could reflect the reduction in pollutant levels, although in absolute terms it was not very great.

- Residents of the congested streets who were badly affected by vehicle exhaust emissions may have moved away before the study began, leaving a preponderance of residents who are relatively unaffected.

- The number of subjects who participated on both occasions was less than expected, and a larger number might have revealed other effects. From the trends in the 
present data, it does not seem likely that such effects would be very great.

- In view of the high proportion of persons who moved or were otherwise lost to follow up, there was scope for selective bias among those who remained, although in fact there was little evidence of differential loss between the two areas.

In summary, the opening of the by-pass produced a reduction in atmospheric pollution in the congested streets, with a proportionate reduction of the lower concentrations in the uncongested streets. The data obtained from the residents suggest that the health effects of these changes are likely to be greater for nasal and ocular symptoms than for lower respiratory symptoms. Some uncertainty about the causality of the observations arises from the low response rates and conflicting trends in respiratory and nasal symptoms, together with the lack of reliability inherent in comparisons between successive questionnaires. There will probably be other opportunities to monitor the effects of relieving traffic congestion, as by-passes and schemes to relieve congestion are planned in various parts of the country. It may be possible to obtain information about the health effects of changes that involve a greater degree of reduction to pollutant exposure than occurred in this study.

\section{ACKNOWLEDGEMENTS}

The study was funded by the Department of Health. We thank Dr Jane Layzell for identifying the congested and uncongested streets, and the local general practitioners for their support.

\section{Authors' affiliations}

M L Burr, B Davies, B A Holmes, K L Williams, University of Wales College of Medicine, Cardiff, UK

G Karani, University of Wales Institute, Cardiff, UK

\section{REFERENCES}

1 Department of Health, Committee on the Medical Effects of Air Pollutants. Handbook on air pollution and health. London: The Stationery Office, 1997.

2 Department of Health, Committee on the Medical Effects of Air Pollutants. Quantification of the effects of air pollution on health in the United Kingdom. London: The Stationery Office, 1998.

3 Nitta H, Sato T, Nakai S, et al. Respiratory health associated with exposure to automobile exhaust. I. Results of cross-sectional studies in 1979, 1982, and 1983. Arch Environ Health 1993:48:53-8.

4 Wist M, Reitmeir P, Dold S, et al. Road traffic and adverse effects on respiratory health in children. BMJ 1993;307:596-600.

5 Edwards J, Walters S, Griffiths RK. Hospital admissions for asthma in preschool children: relationship to major roads in Birmingham, United Kingdom. Arch Environ Health 1994;49:223-7.

6 Weiland SK, Mundt KA, Rückmann A, et al. Self-reported wheezing and allergic rhinitis in children and traffic density on street of residence. Ann Epidemiol 1994;4:243-7.

7 Walters S, Phupinyokul M, Ayres J. Hospital admission rates for asthma and respiratory disease in the West Midlands: their relationship to air pollution levels. Thorax 1995;50:948-54.
8 Duhme H, Weiland SK, Keil U, et al. The association between self-reported symptoms of asthma and allergic rhinitis and self-reported traffic density on street of residence in adolescents. Epidemiology 1996;7:578-82.

9 Brunekreef B, Janssen NAH, de Hartog J, et al. Air pollution from truck traffic and lung function in children living near motorways. Epidemiology 1997; 8:298-303

10 Montefort S, Lenicker HM, Caruna S, et al. Asthma, rhinitis and eczema in Maltese 13-15 year-old schoolchildren-prevalence, severity and associated factors [ISAAC]. Clin Exp Allergy 1998;28:1089-99.

11 Krämer U, Koch T, Ranff U, et al. Traffic-related air pollution is associated with atopy in children living in urban areas. Epidemiology 2000;1 1:64-70.

12 Speizer FE, Ferris BG. Exposure to automobile exhaust. I. Prevalence of respiratory symptoms and disease. Arch Environ Health 1973;26:313-18.

13 Raaschou-Nielsen O, Nielsen ML, Gehl J. Traffic-related air pollution: exposure and health effects in Copenhagen street cleaners and cemetery workers. Arch Environ Health 1995:50:207-13.

14 Kaur B, Anderson HR, Austin J, et al. Prevalence of asthma symptoms, diagnosis, and treatment in 12-14 year old children across Great Britain (international study of asthma and allergies in childhood, ISAAC UK). BMJ 1998;316:118-24.

15 Austin JB, Russell G, Adam MG, et al. Prevalence of asthma and wheeze in the Highlands of Scotland. Arch Dis Child 1994;71:211-16.

16 Devereux G, Ayatollahi T, Ward R, et al. Asthma, airways responsiveness and air pollution in two contrasting districts of northern England. Thorax 1996;51:169-74.

17 Charpin D, Kleisbauer JP, Lanteaume A, et al. Existe-t-il un facteur urbain dans l'asthme et l'allergie? Rev Mal Resp 1988;5:109-14.

18 International Study of Asthma and Allergies in Childhood (ISAAC) Steering Committee. Worldwide variation in prevalence of symptoms of asthma, allergic rhinoconjunctivitis, and atopic eczema: ISAAC. Lancet 1998;351:1225-32.

19 Papageorgiou N, Gaga M, Marossis C, et al. Prevalence of asthma and asthma-like symptoms in Athens, Greece. Respir Med 1997:91:83-8.

20 Waldron G, Pottle B, Dod J. Asthma and the motorways-one district's experience. J Public Health Med 1995; 17:85-9.

21 Livingstone AE, Shaddick G, Grundy C, et al. Do people living near inner city main roads have more asthma? Case-control study. BMJ 1996;312:676-7.

22 Wilkinson P, Elliott P, Grundy C, et al. Case-control study of hospital admission with asthma in children aged 5-14 years: relation with road traffic in north west London. Thorax 1999;54:1070-4.

23 van Wijnen JH, van der Zee SC. Traffic-related air pollutants: exposure of road users and populations living near busy roads. Rev Environ Health 1998; 13:1-25.

24 Newcombe RG. Interval estimation for the difference between independent proportions. A comparative evaluation of eleven methods. Statistics in Medicine 1998;17:873-90

25 Newcombe RG. Improved confidence intervals for the difference between binomial proportions based on paired data. Statistics in Medicine 1998; 17:2635-50.

26 Anderson HR, Atkinson R, Limb ES, et al. Epidemic of asthma was not associated with episode of air pollution. BMJ 1996;312:1606-7.

27 Schwartz J, Neas LM. Fine particles are more strongly associated than coarse particles with acute respiratory health effects in schoolchildren. Epidemiology 2000;11:6-10

28 von Mutius E, Fritzsch C, Weiland SK, et al. Prevalence of asthma and allergic disorders among children in united Germany: a descriptive comparison. BM 1992:305:1395-9.

29 Ishizaki T, Koizumi K, Ikemori R, et al. Studies of prevalence of Japanese cedar pollinosis among the residents in a densely cultivated area. Ann Allergy 1987:58:265-70

30 Mukala K, Pekkanen J, Tiittanen $\mathrm{P}$, et al. Seasonal exposure to $\mathrm{NO}_{2}$ and respiratory symptoms in preschool children. Journal of Exposure Analysis \& Environmental Epidemiology 1996;6:197-210.

31 Rudell B, Ledin M-C, Hammarström U, et al. Effects on symptoms and lung function in humans experimentally exposed to diesel exhaust. Occup Environ Med 1996;53:658-62. 